\title{
Cyst formation after stereotactic radiosurgery for brain arteriovenous malformations: a systematic review
}

\author{
Adeel Ilyas, BA, ${ }^{1}$ Ching-Jen Chen, MD, ${ }^{1}$ Dale Ding, MD, ${ }^{1}$ Panagiotis Mastorakos, MD, ${ }^{1}$ \\ Davis G. Taylor, MD, I. Jonathan Pomeraniec, MD, MBA, ${ }^{1}$ Cheng-Chia Lee, MD, ${ }^{2}$ and \\ Jason Sheehan, MD, PhD ${ }^{1}$ \\ 1Department of Neurological Surgery, University of Virginia Health System, Charlottesville, Virginia; and 2Department of \\ Neurological Surgery, Taipei Veterans General Hospital, Taipei, Taiwan
}

\begin{abstract}
OBJECTIVE Cyst formation can occasionally occur after stereotactic radiosurgery (SRS) for brain arteriovenous malformations (AVMs). Given the limited data regarding post-SRS cyst formation in patients with AVM, the time course, natural history, and management of this delayed complication are poorly defined. The aim of this systematic review was to determine the incidence, time course, and optimal management of cyst formation after SRS for AVMs.

METHODS A literature review was performed using PubMed to identify studies reporting cyst formation in AVM patients treated with SRS. Baseline and outcomes data, including the incidence and management of post-SRS cysts, were extracted from each study that reported follow-up duration. The mean time to cyst formation was calculated from the subset of studies that reported individual patient data.

RESULTS Based on pooled data from 22 studies comprising the incidence analysis, the overall rate of post-SRS cyst formation was $3.0 \%$ (78/2619 patients). Among the 26 post-SRS cyst patients with available AVM obliteration data, nidal obliteration was achieved in $20(76.9 \%)$. Of the 64 cyst patients with available symptomatology and management data, 21 (32.8\%) were symptomatic; 21 cysts (32.8\%) were treated with surgical intervention, whereas the remaining 43 $(67.2 \%)$ were managed conservatively. Based on a subset of 19 studies reporting individual time-to-cyst-formation data from 63 patients, the mean latency period to post-SRS cyst formation was 78 months (6.5 years).
\end{abstract}

CONCLUSIONS Cyst formation is an uncommon complication after SRS for AVMs, with a relatively long latency period. The majority of post-SRS cysts are asymptomatic and can be managed conservatively, although enlarging or symptomatic cysts may require surgical intervention. Long-term follow-up of AVM patients is crucial to the appropriate diagnosis and management of post-SRS cysts.

https://thejns.org/doi/abs/10.3171/2016.12.JNS162478

KEY WORDS cyst; stereotactic radiosurgery; arteriovenous malformation; complication; incidence

$\mathrm{S}$ TEREOTACTIC radiosurgery (SRS) is widely used as a treatment option for brain arteriovenous malformations (AVMs), particularly for small- to moderate-sized nidi located in deep or eloquent brain areas associated with an elevated surgical risk. ${ }^{10,11,16,25,49,60}$ Cyst formation after SRS for AVM is an uncommon, delayed complication, which can become symptomatic and necessitate surgical intervention. . $^{34,42,54,55,63,64}$ The current literature on post-SRS cyst formation in AVM patients is limited by a paucity of studies reporting the incidence of cyst formation, the prolonged temporal relationship between SRS and cyst formation, and the clinical manifestations and management of post-SRS cysts. $.7,7,14,22,27,28,32,35-37,41,42,54$, 63,64,69 Additionally, there is considerable variation in the data regarding cyst formation because of differences in baseline patient and AVM characteristics, SRS modalities and treatment strategies, follow-up durations, and reporting of radiological and clinical end points. ${ }^{4,30,35,44,54}$ Overlap of study cohorts further confounds our ability to ascertain meaningful relationships between preoperative

ABBREVIATIONS AVM = arteriovenous malformation; GKRS = Gamma Knife radiosurgery; LINAC = linear accelerator; RIC = radiation-induced change; SRS = stereotactic radiosurgery.

SUBMITTED September 26, 2016. ACCEPTED December 5, 2016.

INCLUDE WHEN CITING Published online May 26, 2017; DOI: 10.3171/2016.12.JNS162478. 
factors and post-SRS cyst formation. ${ }^{26,34,54}$ Therefore, the aims of this systematic review were to 1) quantify the incidence of cyst formation after SRS for AVM, 2) determine the latency period between AVM SRS and cyst formation, and 3) evaluate the management options for post-SRS cysts in AVM patients.

\section{Methods}

\section{Literature Search and Inclusion Criteria}

This review follows the guidelines set forth by the Preferred Reporting Items for Systematic Reviews and Meta-Analyses (PRISMA) Statement. A literature review was performed using PubMed on September 1, 2016, with the following search phrase: "arteriovenous malformations AND radiosurgery AND cyst." The studies were screened by title and abstract to ascertain fulfillment of inclusion criteria, which were as follows: 1) number of AVM patients who developed a cyst after SRS was reported; 2) each patient with a post-SRS cyst was represented only once among all of the studies included for analysis; 3) size of the overall cohort of AVM patients treated with SRS was reported; 4) patients were treated with SRS using the Gamma Knife (GKRS), linear accelerator (LINAC), or proton beam systems, in a single session or a dose- or volume-staged approach; 5) follow-up duration after SRS was reported; and 6) study was written in English. To meet the aforementioned inclusion criteria, only the most recent study with the greatest number of patients diagnosed with post-SRS cysts was used from a set of overlapping studies.

\section{Data Extraction}

Patient demographics, AVM characteristics, SRS treatment parameters, and outcome and complication data were extracted from each of the eligible studies. Demographic data included the number of AVM patients treated with SRS, sex, age, and follow-up duration. Arteriovenous malformation characteristics included nidus volume, prior AVM hemorrhage, and prior nidal embolization. Stereotactic radiosurgery treatment parameters included margin dose, maximum dose, and isodose line. Outcome and complication data included AVM obliteration, time to obliteration, post-SRS cyst formation, latency period between SRS and cyst formation, symptomatic radiationinduced changes (RICs), post-SRS hemorrhage, and death. Radiation-induced changes were defined as perinidal T2weighted hyperintensities on follow-up MRI, and only clinically symptomatic RICs were recorded from each study. For those patients who developed post-SRS cysts, data regarding the time interval between SRS and cyst formation, association with complete nidal obliteration, presence or absence of symptoms associated with the cyst, and management of the cyst were recorded, when available. We defined post-SRS cyst formation as the de novo development of a fluid-filled, proteinaceous, and/or hemorrhagic sac within or adjacent to the site of the original AVM nidus.

\section{Statistical Analysis}

All statistical analyses were performed using MATLAB (version R2016a, MathWorks). For studies included in the analysis of cyst incidence, descriptive statistics were calculated for baseline and post-SRS outcomes data. PostSRS cyst data were pooled from all eligible studies for the calculation of cyst incidence. The incidence of cyst formation was calculated by dividing the total number of AVM patients who developed a cyst after SRS by the total number of AVM patients treated with SRS. For the studies with individual patient data regarding the time interval between SRS and cyst formation, the mean latency period to cyst formation was calculated.

\section{Results \\ Study Selection}

The literature search yielded a total of 59 studies, from which 52 were selected based on title and abstract; 20 studies were then eliminated based on a failure to meet the inclusion criteria, yielding 32 studies eligible for at least one analysis. Of the 32 eligible studies, 22 studies reported sufficient data to allow inclusion in the analysis for postSRS cyst incidence, and 19 studies reported sufficient data to allow inclusion in the analysis for latency period to cyst formation (Fig. 1).

\section{Overall Demographic and Treatment Characteristics}

Table 1 summarizes the patient, AVM, and treatment characteristics of the 22 studies, comprising a total of 2619 AVM patients treated with SRS, which were included in the cyst incidence analysis. The frequency of the female sex was $46.8 \%$ (962/2053 patients). The median age ranged from 12 to 46 years. The median AVM volume ranged from 1.4 to $48.8 \mathrm{~cm}^{3}$. Prior AVM hemorrhage had occurred in $41.8 \%$ of patients $(920 / 2200)$, and the proportion of ruptured AVMs ranged from $0 \%$ to $83.3 \%$, among the studies. Prior embolization had been performed in $21.6 \%$ of patients (462/2135 patients), and the proportion of embolized AVMs ranged from $0 \%$ to $100.0 \%$.

Gamma Knife radiosurgery was exclusively used in 20 studies (90.9\%), and LINAC was exclusively used in 2 studies (9.1\%). Volume-staged SRS was used in 1 study, dose-staged or hypofractionated SRS was used in 1 study, and repeat SRS was used in 2 studies. The median margin and maximum doses ranged from 16 to $24 \mathrm{~Gy}$ and 28 to $44 \mathrm{~Gy}$, respectively. The median isodose line ranged from $50 \%$ to $80 \%$. The median follow-up duration of all SRStreated AVM patients in each cohort ranged from 31 to 199 months (2.6-16.6 years).

\section{Cyst Formation Incidence, Latency, and Management}

The data regarding post-SRS cyst formation are summarized in Table 2. The mean incidence of cyst formation for all studies was 4.4\% (95\% CI 2.0\%-6.8\%). Cyst formation rates were $4.1 \%$ (95\% CI $1.5 \%-6.7 \%)$ in the 20 studies using GKRS, compared with $6.9 \%$ (95\% CI 6.4\%$7.4 \%$ ) in the 2 studies using LINAC. Based on pooled data, the incidence of post-SRS cyst formation was 3.0\% (78/2619 patients) for all studies. The pooled rates of cyst formation were $2.9 \%$ (74/2562 patients) in the studies using GKRS and 7.0\% (4/57 patients) in the studies using LINAC. Of the 26 post-SRS cysts for which AVM oblit- 


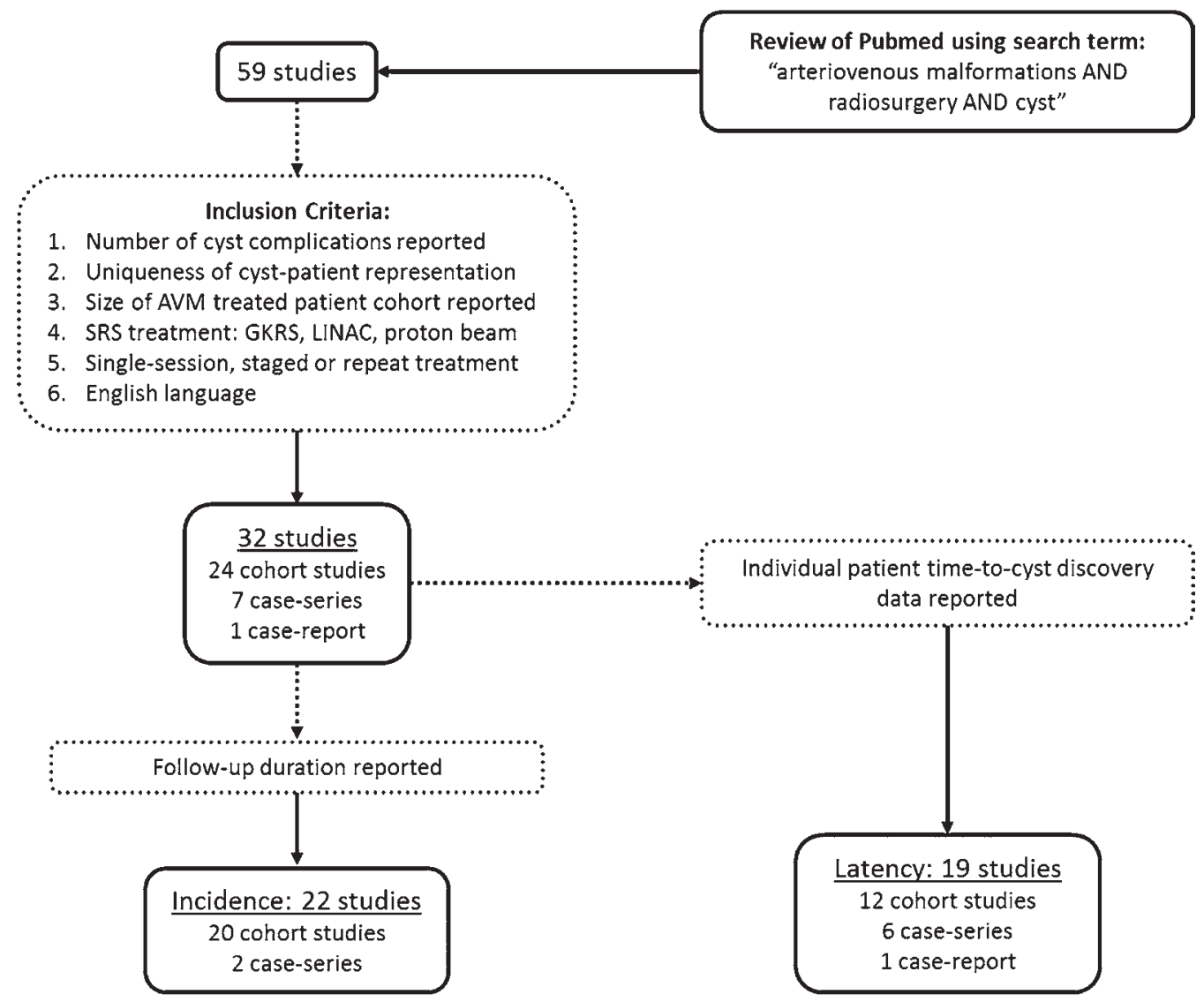

FIG. 1. Flow diagram showing the selection process for studies included in analyses of cyst incidence and latency period.

eration data were available, $76.9 \%$ (20/26) were associated with complete nidal obliteration. Of 64 post-SRS cysts for which the symptomatology and management data were reported, 32.8\% (21/64) were symptomatic. Of these 64 cysts, 16 cases $(25.0 \%)$ underwent craniotomy for cyst resection, 4 (6.2\%) underwent stereotactic decompression, 3 (4.7\%) underwent cystoperitoneal shunt placement, and 1 (1.6\%) underwent Ommaya reservoir placement. In total, 21 patients underwent surgical intervention (32.8\%), and the remaining $43(67.2 \%)$ were managed conservatively. Specific symptoms were attributed to 6 post-SRS cysts and included seizures (3 [50.0\%] of 6 cysts), hemiparesis (2 [33.3\%] of 6 cysts), psychological changes (1 [16.7\%] of 6 cysts), aphasia (1 [16.7\%] of 6 cysts), headache (1 [16.7\%] of 6 cysts), and death secondary to status epilepticus (1 [16.7\%] of 6 cysts).

Table 3 summarizes the time-to-cyst-formation data from the 19 studies that reported individual patient data, comprising a total of 63 patients with post-SRS cysts. The mean latency period between SRS and cyst formation was 78 months (6.5 years), and individual latency periods ranged from 6 to 240 months ( $0.5-12.0$ years). Figure 2 is a histogram of the incidence of cyst formation in these 63 patients.

\section{Obliteration and Complication Rates}

The posttreatment data from the 21 studies included in the cyst incidence analysis are summarized in Table 2. The mean complete AVM obliteration rate was $65.4 \%$ (95\% CI 56.3\%-74.6\%). Based on pooled data, obliteration was achieved in $65.5 \%$ (1450/2215 patients). The median time to obliteration ranged from 2.5 to 8.3 years. The mean rates of symptomatic RIC, post-SRS hemorrhage, and mortality were $8.5 \%$ (95\% CI $4.9 \%-12.0 \%), 13.2 \%$ (95\% CI $3.3 \%-23.2 \%$ ), and $6.9 \%$ (95\% CI $4.1 \%-9.8 \%$ ), respectively. Based on pooled data, the rates of symptomatic RIC, post-SRS hemorrhage, and mortality were $8.6 \%$ (165/1907 patients), $8.8 \%$ (191/2162 patients), and 6.0\% (92/1542 patients), respectively.

\section{Discussion}

Cyst formation following SRS treatment of AVM is one of the least common complications..$^{18,24,54,61}$ Because of its relative rarity and the prolonged follow-up duration necessary to detect its occurrence, the pathobiology, clinical implications, and overall impact of delayed cyst formation on the risk-to-benefit profile of SRS for AVM remain incompletely defined..$^{50,58}$ Given our synthesis of the available literature, we estimate that approximately $3 \%$ of AVM patients will develop a cyst after SRS. However, since $70 \%$ of post-SRS cysts were asymptomatic, the rate of symptomatic cyst formation after SRS for an AVM may only be $1 \%$. 


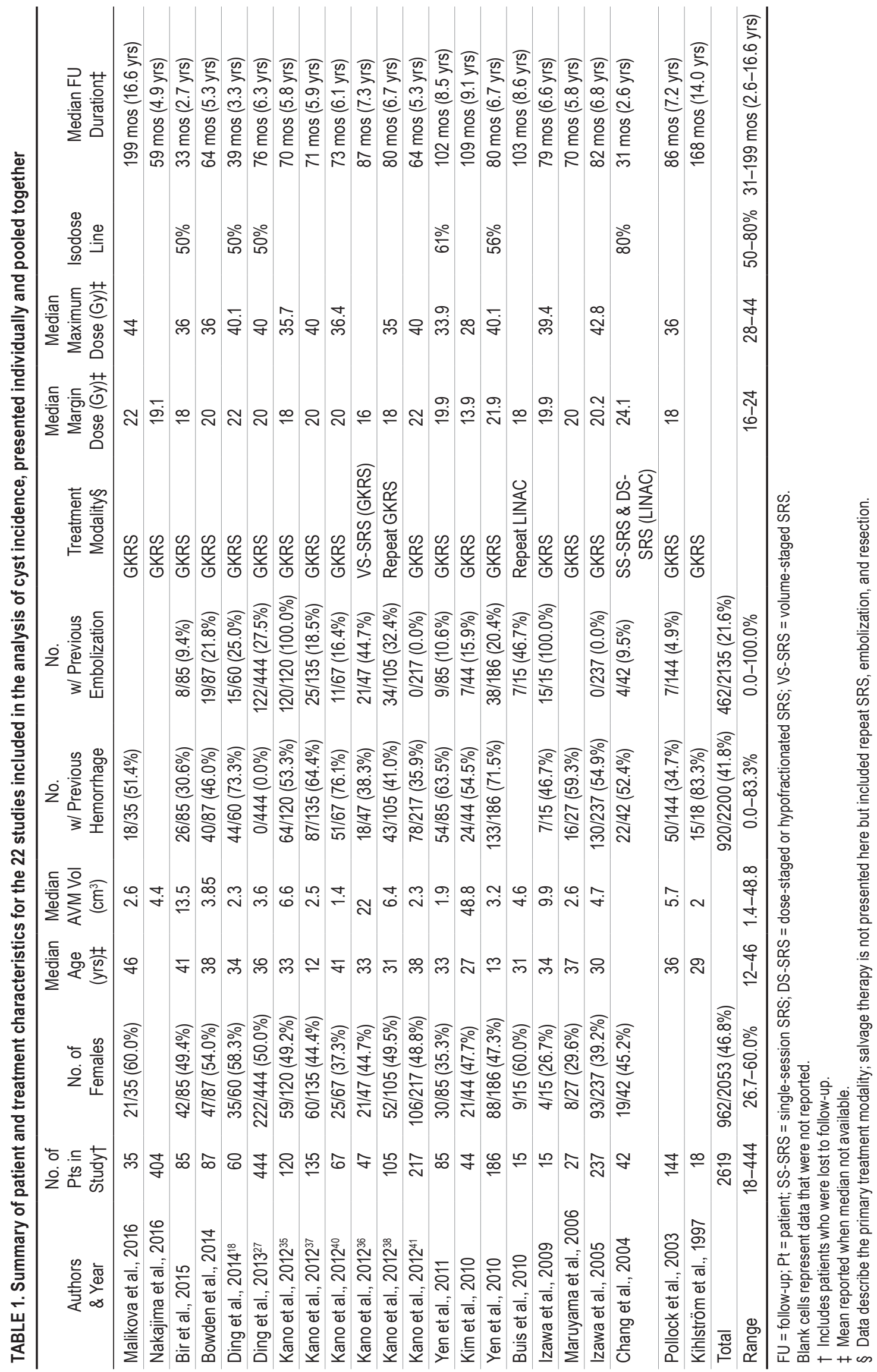




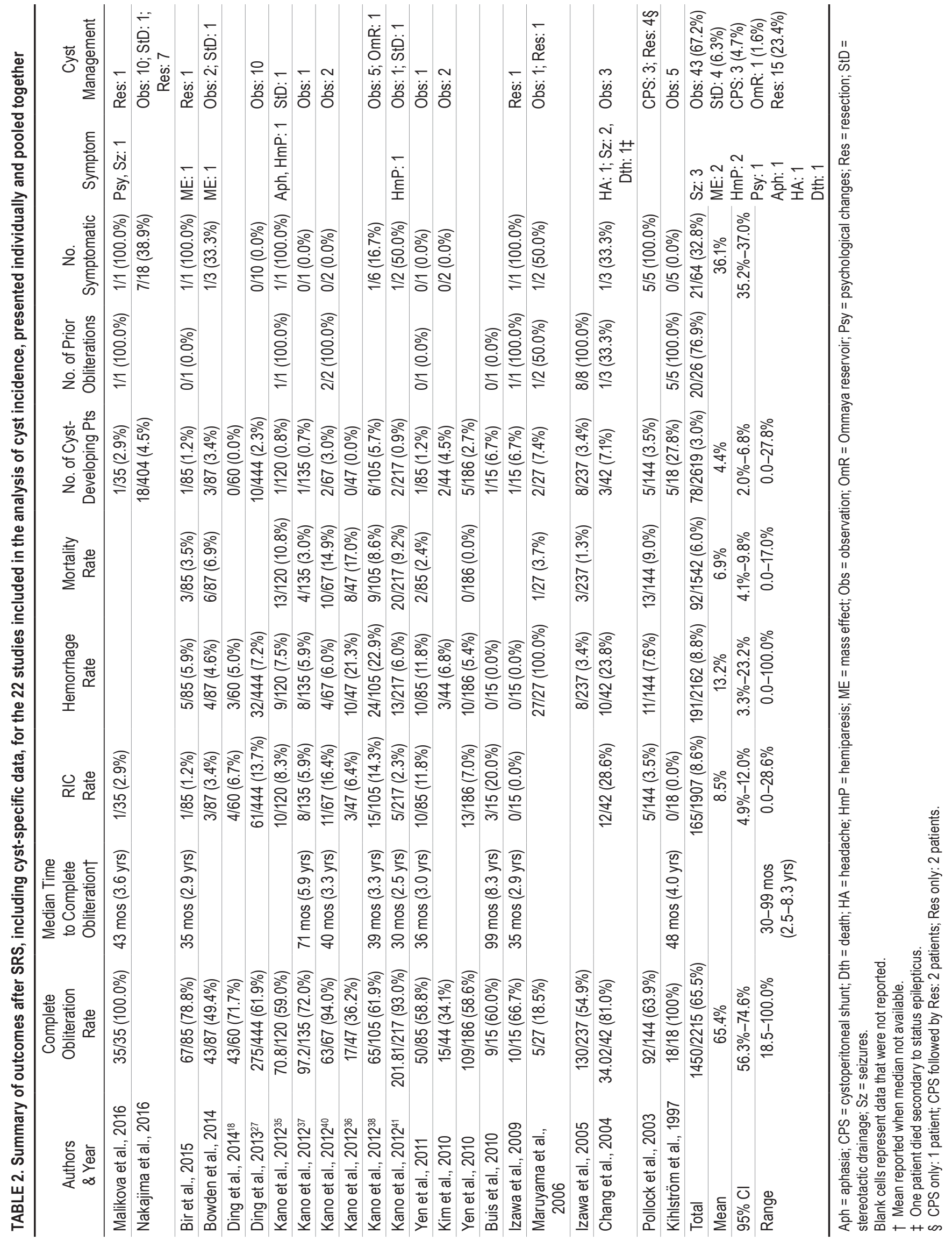


TABLE 3. Time to cyst formation for 63 patients from the 19 studies reporting individual patient data for follow-up after SRS

\begin{tabular}{|c|c|c|}
\hline Authors \& Year & Pt No. & Time to Cyst (mos) \\
\hline Malikova et al., 2016 & 1 & 240 \\
\hline Bir et al., 2015 & 2 & 12 \\
\hline \multirow[t]{28}{*}{ Shuto et al., 2015} & 3 & 13.2 \\
\hline & 4 & 31.2 \\
\hline & 5 & 37.2 \\
\hline & 6 & 38.4 \\
\hline & 7 & 42 \\
\hline & 8 & 42 \\
\hline & 9 & 49.2 \\
\hline & 10 & 54 \\
\hline & 11 & 54 \\
\hline & 12 & 60 \\
\hline & 13 & 60 \\
\hline & 14 & 60 \\
\hline & 15 & 64.8 \\
\hline & 16 & 74.4 \\
\hline & 17 & 74.4 \\
\hline & 18 & 85.2 \\
\hline & 19 & 94.8 \\
\hline & 20 & 97.2 \\
\hline & 21 & 97.2 \\
\hline & 22 & 121.2 \\
\hline & 23 & 123.6 \\
\hline & 24 & 134.4 \\
\hline & 25 & 135.6 \\
\hline & 26 & 144 \\
\hline & 27 & 144 \\
\hline & 28 & 162 \\
\hline & 29 & 180 \\
\hline & 30 & 192 \\
\hline \multirow[t]{3}{*}{ Bowden et al., 2014} & 31 & 6 \\
\hline & 32 & 31 \\
\hline & 33 & 67 \\
\hline \multirow[t]{5}{*}{ Matsuo et al., 2014} & 34 & 8 \\
\hline & 35 & 39.6 \\
\hline & 36 & 50.4 \\
\hline & 37 & 60 \\
\hline & 38 & 126 \\
\hline Kano et al., $2012^{35}$ & 39 & 8 \\
\hline Kano et al., $2012^{37}$ & 40 & 56 \\
\hline \multirow[t]{2}{*}{ Kano et al., $2012^{40}$} & 41 & 8.8 \\
\hline & 42 & 166 \\
\hline \multirow[t]{2}{*}{ Kano et al., $2012^{41}$} & 43 & 38 \\
\hline & 44 & 74 \\
\hline \multirow[t]{3}{*}{ Al Hinai et al., 2011} & 45 & 36 \\
\hline & 46 & 144 \\
\hline & 47 & 156 \\
\hline Yen et al., 2011 & 48 & 72 \\
\hline
\end{tabular}

CONTINUED IN NEXT COLUMN 》

\section{» CONTINUED FROM PREVIOUS COLUMN}

TABLE 3. Time to cyst formation for 63 patients from the 19 studies reporting individual patient data for follow-up after SRS

\begin{tabular}{lcc}
\hline \multicolumn{1}{c}{ Authors \& Year } & Pt No. & Time to Cyst (mos) \\
\hline Buis et al., 2010 & 49 & 47 \\
\hline Kim et al., 2010 & 50 & 36 \\
\hline & 51 & 42 \\
\hline Izawa et al., 2009 & 52 & 72 \\
\hline Liu et al., 2008 & 53 & 60 \\
\hline Inoue, 2006 & 54 & 120 \\
\hline Flickinger et al., 1999 & 55 & 57 \\
\hline & 56 & 64 \\
\hline & 57 & 83 \\
\hline & 58 & 84 \\
\hline & 59 & 120 \\
\hline Kim et al., 1999 & 60 & 11 \\
\hline Yamamoto et al., 199863 & 61 & 60 \\
\hline & 62 & 84 \\
\hline & 63 & 120 \\
\hline
\end{tabular}

Mean latency of cyst formation: 78.2 mos (6.5 yrs).

\section{Factors Associated With Post-SRS Cyst Formation}

We found a mean latency period of 6.5 years between SRS and cyst formation. In general, cyst formation occurs later than more common post-SRS complications, such as RICs and post-SRS hemorrhage. ${ }^{19,20,21,23,29,53,67}$ Therefore, studies with longer follow-up periods tended to report a higher incidence of cyst formation, which emphasizes the importance of long-term surveillance after SRS for AVM. Specifically, patients who develop new neurological symptoms after AVM obliteration should undergo neuroimaging to screen for cyst formation. Pan et al. reported an overall post-SRS cyst incidence of $1.6 \%$, which increased to $3.6 \%$ if only those patients with at least 5 years of follow-up were considered. ${ }^{54}$ This suggests that the rate of cyst detection may positively correlate with follow-up duration.

Several demographic factors, AVM angioarchitectural features, treatment parameters, and post-SRS outcomes have been associated with cyst formation. ${ }^{26,34,54}$ Ding et al. reported a cyst incidence of $2.3 \%$ at a mean follow-up of 7.9 years in a cohort of 444 unruptured AVMs; in their analysis, radiological evidence of RIC was significantly associated with cyst formation. ${ }^{22}$ Izawa et al. reported a cyst incidence of $3.4 \%$ at a mean follow-up of 6.8 years; their analysis found higher SRS maximal dose, larger nidus volume, lobar AVM location, and obliteration to be predictors of cyst formation. ${ }^{34}$ In our analysis, we found that the majority of post-SRS cysts (77\%) occurred in patients with obliterated nidi, which suggests that follow-up of AVM patients treated with SRS should not be abandoned after obliteration is achieved. Pan et al. found RIC and prior nidal embolization to be significantly associated with cyst formation, while the relationship between prior AVM hemorrhage and cyst formation approached 


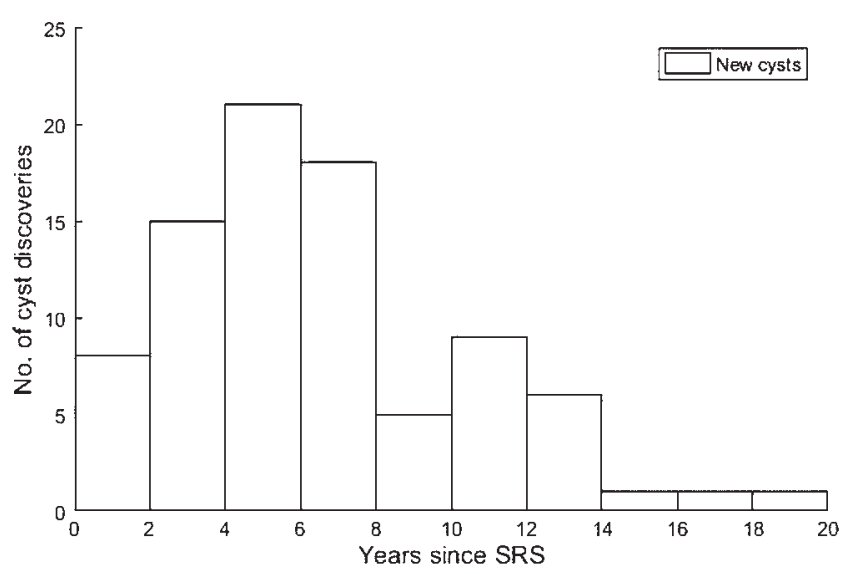

FIG. 2. Histogram of the number of newly discovered cysts biennially since SRS treatment in 63 patients from 19 studies with individual patient time-to-cyst-discovery data. The mean time to cyst formation is 78 months (6.5 years).

statistical significance. ${ }^{54}$ These findings suggest that the pathophysiology of delayed cyst formation is distinct from that of post-SRS hemorrhage. . $^{215,34,65,66}$ Indeed, histopathological examination of resected cysts suggests that cyst formation occurs secondary to a chronic, organized response to radiation-induced vascular telangiectasia and wall damage, which promotes microhemorrhage and protein exudation..$^{59}$ It is possible that prior AVM hemorrhage and embolization increase tissue susceptibility to damage, thereby increasing the risk of cyst formation. ${ }^{6,52}$ The risk of cyst formation was found to be higher for AVM patients treated with LINAC than in those treated with GKRS (7\% vs $3 \%$, respectively, in the pooled analysis). Because of the insufficient statistical power of the available literature, additional data are necessary to perform a more rigorous evaluation of the relationship between the SRS treatment modality and cyst formation. Differences in dosimetry not only in the immediate planned target volume but also at the lower isodose lines such as the 12-Gy isodose volume should be examined as potential contributing factors for discrepancies in cyst formation between SRS delivery platforms.

Kihlström et al. reported the highest rate of cyst formation (28\%) among the studies included in our analysis, a rate that was more than 3 times higher than the second highest rate of cyst incidence $(7.4 \%)$ documented by Maruyama et al. ${ }^{42,47} \mathrm{We}$ offer the following observations to put these findings into perspective. First, the Kihlström study had a particularly lengthy mean follow-up duration of 14 years. Second, only patients who attained complete AVM obliteration were included in that study, and cyst formation may correlate with nidal occlusion. ${ }^{34}$ Third, their study reported the highest proportion of ruptured AVMs treated with SRS (83.3\%) among the included studies. Since prior AVM hemorrhage may be correlated with cyst formation, the high rate of prior hemorrhage could also partially account for the elevated post-SRS cyst incidence. ${ }^{54}$ However, all 5 cysts in the study were between 1 and $2 \mathrm{~cm}$ in diameter, asymptomatic, and managed conservatively.

\section{Management of Post-SRS Cysts}

The optimal management of post-SRS cysts is not well defined. In general, asymptomatic cysts should be managed conservatively, and some cysts have been shown to spontaneously regress over time. However, enlarging cysts may require treatment, even in the absence of symptoms, particularly if the cyst is located in the vicinity of deep or eloquent brain area. ${ }^{28,47,59,62}$ Significant mass effect secondary to the cyst, intracystic loculations and septations, and residual AVM nidus adjacent to the cyst are all factors that may favor craniotomy for cyst resection. ${ }^{33,55}$ Simple cyst anatomy, significant medical comorbidities, or refusal of craniotomy may favor cystoperitoneal shunt or Ommaya reservoir placement. Stereotactic drainage alone may be less effective than shunting since cysts have the potential to recur. ${ }^{51,55}$

Currently, no medical therapy is known to be effective for post-SRS cysts given our incomplete understanding of cyst pathogenesis. Shuto et al. analyzed the histopathology of 28 post-SRS cysts and identified angiogenic and inflammatory components. ${ }^{59}$ These authors postulated that post-SRS cysts were on the opposite end of the same pathobiological spectrum as chronic encapsulating hematomas. Future studies may seek to investigate the effect of antiangiogenic (for example, bevacizumab) or antiinflammatory (for example, dexamethasone) medications on cyst size and morphology.12

In the context of the aforementioned surgical and medical therapeutic uncertainty regarding optimal cyst management, we recommend surgical intervention for an enlarging cyst with a volume $>8 \mathrm{~cm}^{3}$ and for any cyst causing newfound neurological signs or symptoms. Specifically, we typically recommend shunt placement or aspiration for deep-seated cysts and resection for superficially located ones. Small, asymptomatic cysts can generally be observed with serial neuroimaging studies and correlated with the patient's neurological examination.

\section{Study Limitations}

Heterogeneity of the baseline and outcomes data among the studies limits our ability to draw definitive conclusions regarding the incidence of cyst formation after SRS for AVM. Variability in follow-up durations after SRS may affect our estimates of cyst incidence. Specifically, the inclusion of studies with a median follow-up of less than 5 years may have resulted in an underestimation of cyst incidence, whereas reporting bias of cyst complications may have resulted in an overestimation. Additionally, given the paucity of data regarding post-SRS cysts, we included studies that used a variety of both primary SRS treatment paradigms and salvage therapies. ${ }^{3,49}$

Several of the studies included in this review identified various risk factors for cyst formation (for example, RIC, SRS dose, AVM volume and location, obliteration rate, and prior nidal embolization). Unfortunately, given the lack of individual patient data, especially for patients who did not develop post-SRS cysts, we were unable to perform analyses of the pooled data to identify predictors of cyst formation. Specifically, we were unable to ascertain the effect of nidal morphology, SRS dose planning, number and timing of SRS treatments, and time interval between prior AVM 
interventions and SRS on cyst formation. Additionally, the lack of sufficient granularity with respect to individual patient data prevented us from performing a time-dependent analysis (for example, Kaplan-Meier method) for cyst formation. We were unable to ascertain the specific clinical manifestations of symptomatic cysts (for example, seizure, focal neurological deficit, headache). ${ }^{9,13,14,17,57}$ The safety, efficacy, and durability of the various surgical options for cysts requiring intervention could not be determined. All studies were retrospective in design, and unclear risks of bias were assumed for retrospective studies.

\section{Conclusions}

The incidence of cyst formation after SRS for AVM is $3 \%$, with a latency period of approximately 7 years. Therefore, long-term follow-up is paramount for AVM patients treated with SRS because of the substantial delay between treatment and cyst development. The majority of post-SRS cysts are asymptomatic and require only observation. Surgical intervention should be considered for symptomatic or enlarging cysts, with options including craniotomy for resection, cystoperitoneal shunt placement, stereotactic drainage, and Ommaya reservoir implantation.

\section{References}

1. Al Hinai Q, Tampieri D, Souhami L, Sadikot A, Sinclair D, Leblanc R: Cyst formation following radiosurgery for AVMs: report of 3 cases. Can J Neurol Sci 38:734-740, 2011

2. Arslan I, Tezcanli E, Yilmaz M, Cizmeli O, Sengoz M, Peker S: Gamma Knife radiosurgery for arteriovenous malformations: clinical series of 199 patients. Turk Neurosurg [epub ahead of print], 2015

3. Awad AJ, Walcott BP, Stapleton CJ, Ding D, Lee CC, Loeffler JS: Repeat radiosurgery for cerebral arteriovenous malformations. J Clin Neurosci 22:945-950, 2015

4. Bir SC, Ambekar S, Maiti TK, Nanda A: Clinical outcome and complications of Gamma Knife radiosurgery for intracranial arteriovenous malformations. J Clin Neurosci 22:1117-1122, 2015

5. Bowden G, Kano H, Tonetti D, Niranjan A, Flickinger J, Arai Y, et al: Stereotactic radiosurgery for sylvian fissure arteriovenous malformations with emphasis on hemorrhage risks and seizure outcomes. J Neurosurg 121:637-644, 2014

6. Buell TJ, Ding D, Starke RM, Webster Crowley R, Liu KC: Embolization-induced angiogenesis in cerebral arteriovenous malformations. J Clin Neurosci 21:1866-1871, 2014

7. Buis DR, Meijer OWM, van den Berg R, Lagerwaard FJ, Bot JCJ, Slotman BJ, et al: Clinical outcome after repeated radiosurgery for brain arteriovenous malformations. Radiother Oncol 95:250-256, 2010

8. Chang TC, Shirato H, Aoyama H, Ushikoshi S, Kato N, Kuroda $S$, et al: Stereotactic irradiation for intracranial arteriovenous malformation using stereotactic radiosurgery or hypofractionated stereotactic radiotherapy. Int J Radiat Oncol Biol Phys 60:861-870, 2004

9. Chen CJ, Chivukula S, Ding D, Starke RM, Lee CC, Yen CP, et al: Seizure outcomes following radiosurgery for cerebral arteriovenous malformations. Neurosurg Focus 37(3):E17, 2014

10. Cohen-Inbar O, Ding D, Chen CJ, Sheehan JP: Stereotactic radiosurgery for deep intracranial arteriovenous malformations, part 1: Brainstem arteriovenous malformations. J Clin Neurosci 24:30-36, 2016

11. Cohen-Inbar O, Ding D, Sheehan JP: Stereotactic radiosur- gery for deep intracranial arteriovenous malformations, part 2: Basal ganglia and thalamus arteriovenous malformations. J Clin Neurosci 24:37-42, 2016

12. Ding D: Pathogenesis of radiosurgery-induced cyst formation in patients with cerebral arteriovenous malformations. Acta Neurochir (Wien) 157:775-777, 2015

13. Ding D, Quigg M, Starke RM, Xu Z, Yen CP, Przybylowski CJ, et al: Radiosurgery for temporal lobe arteriovenous malformations: effect of temporal location on seizure outcomes. J Neurosurg 123:924-934, 2015

14. Ding D, Quigg M, Starke RM, Yen CP, Przybylowski CJ, Dodson BK, et al: Cerebral arteriovenous malformations and epilepsy, part 2: predictors of seizure outcomes following radiosurgery. World Neurosurg 84:653-662, 2015

15. Ding D, Starke RM, Kano H, Lee JYK, Mathieu D, Pierce J, et al: Stereotactic radiosurgery for Spetzler-Martin Grade III arteriovenous malformations: an international multicenter study. J Neurosurg [epub ahead of print April 15, 2016. DOI: 10.3171/2016.1.JNS152564]

16. Ding D, Starke RM, Kano H, Mathieu D, Huang P, Kondziolka D, et al: Radiosurgery for cerebral arteriovenous malformations in A Randomized Trial of Unruptured Brain Arteriovenous Malformations (ARUBA)-eligible patients: a multicenter study. Stroke 47:342-349, 2016

17. Ding D, Starke RM, Quigg M, Yen CP, Przybylowski CJ, Dodson BK, et al: Cerebral arteriovenous malformations and epilepsy, part 1: predictors of seizure presentation. World Neurosurg 84:645-652, 2015

18. Ding D, Starke RM, Yen CP, Sheehan JP: Radiosurgery for cerebellar arteriovenous malformations: does infratentorial location affect outcome? World Neurosurg 82:e209-e217, 2014

19. Ding D, Xu Z, Shih HH, Starke RM, Yen CP, Sheehan JP: Stereotactic radiosurgery for partially resected cerebral arteriovenous malformations. World Neurosurg 85:263-272, 2016

20. Ding D, Xu Z, Starke RM, Yen CP, Shih HH, Buell TJ, et al: Radiosurgery for cerebral arteriovenous malformations with associated arterial aneurysms. World Neurosurg 87:77-90, 2016

21. Ding D, Xu Z, Yen CP, Starke RM, Sheehan JP: Radiosurgery for cerebral arteriovenous malformations in elderly patients: effect of advanced age on outcomes after intervention. World Neurosurg 84:795-804, 2015

22. Ding D, Xu Z, Yen CP, Starke RM, Sheehan JP: Radiosurgery for unruptured cerebral arteriovenous malformations in pediatric patients. Acta Neurochir (Wien) 157:281-291, 2015

23. Ding D, Yen CP, Starke RM, Xu Z, Sheehan JP: Effect of prior hemorrhage on intracranial arteriovenous malformation radiosurgery outcomes. Cerebrovasc Dis 39:53-62, 2015

24. Ding D, Yen CP, Starke RM, Xu Z, Sheehan JP: Radiosurgery for ruptured intracranial arteriovenous malformations. J Neurosurg 121:470-481, 2014

25. Ding D, Yen CP, Starke RM, Xu Z, Sun X, Sheehan JP: Radiosurgery for Spetzler-Martin Grade III arteriovenous malformations. J Neurosurg 120:959-969, 2014

26. Ding D, Yen CP, Xu Z, Starke RM, Sheehan JP: Radiosurgery for patients with unruptured intracranial arteriovenous malformations. J Neurosurg 118:958-966, 2013

27. Ding D, Yen CP, Xu Z, Starke RM, Sheehan JP: Radiosurgery for primary motor and sensory cortex arteriovenous malformations: outcomes and the effect of eloquent location. Neurosurgery 73:816-824, 2013

28. Flickinger JC, Kondziolka D, Lunsford LD, Pollock BE, Yamamoto M, Gorman DA, et al: A multi-institutional analysis of complication outcomes after arteriovenous malformation radiosurgery. Int J Radiat Oncol Biol Phys 44:67-74, 1999

29. Flickinger JC, Kondziolka D, Pollock BE, Maitz AH, Lun- 
sford LD: Complications from arteriovenous malformation radiosurgery: multivariate analysis and risk modeling. Int J Radiat Oncol Biol Phys 38:485-490, 1997

30. Hara M, Nakamura M, Shiokawa Y, Sawa H, Sato E, Koyasu $\mathrm{H}$, et al: Delayed cyst formation after radiosurgery for cerebral arteriovenous malformation: two case reports. Minim Invasive Neurosurg 41:40-45, 1998

31. Inoue HK: Long-term results of Gamma Knife surgery for arteriovenous malformations: 10 - to 15 -year follow up in patients treated with lower doses. J Neurosurg 105 Suppl:64-68, 2006

32. Izawa M, Chernov M, Hayashi M, Iseki H, Hori T, Takakura $\mathrm{K}$ : Combined management of intracranial arteriovenous malformations with embolization and Gamma Knife radiosurgery: comparative evaluation of the long-term results. Surg Neurol 71:43-53, 2009

33. Izawa M, Chernov M, Hayashi M, Nakaya K, Kamikawa S, Kato K, et al: Management and prognosis of cysts developed on long-term follow-up after Gamma Knife radiosurgery for intracranial arteriovenous malformations. Surg Neurol 68:400-406, 2007

34. Izawa M, Hayashi M, Chernov M, Nakaya K, Ochiai T, Murata N, et al: Long-term complications after Gamma Knife surgery for arteriovenous malformations. J Neurosurg 102 Suppl:34-37, 2005

35. Kano H, Kondziolka D, Flickinger JC, Park KJ, Iyer A, Yang $\mathrm{HC}$, et al: Stereotactic radiosurgery for arteriovenous malformations after embolization: a case-control study. J Neurosurg 117:265-275, 2012

36. Kano H, Kondziolka D, Flickinger JC, Park KJ, Parry PV, Yang HC, et al: Stereotactic radiosurgery for arteriovenous malformations, Part 6: multistaged volumetric management of large arteriovenous malformations. J Neurosurg 116:5465,2012

37. Kano H, Kondziolka D, Flickinger JC, Yang HC, Flannery TJ, Awan NR, et al: Stereotactic radiosurgery for arteriovenous malformations, part 2: management of pediatric patients. J Neurosurg Pediatr 9:1-10, 2012

38. Kano H, Kondziolka D, Flickinger JC, Yang HC, Flannery TJ, Awan NR, et al: Stereotactic radiosurgery for arteriovenous malformations, Part 3: outcome predictors and risks after repeat radiosurgery. J Neurosurg 116:21-32, 2012

39. Kano H, Kondziolka D, Flickinger JC, Yang HC, Flannery TJ, Niranjan A, et al: Stereotactic radiosurgery for arteriovenous malformations, Part 4: management of basal ganglia and thalamus arteriovenous malformations. J Neurosurg 116:33-43, 2012

40. Kano H, Kondziolka D, Flickinger JC, Yang HC, Flannery TJ, Niranjan A, et al: Stereotactic radiosurgery for arteriovenous malformations, Part 5: management of brainstem arteriovenous malformations. J Neurosurg 116:44-53, 2012

41. Kano H, Lunsford LD, Flickinger JC, Yang HC, Flannery TJ, Awan NR, et al: Stereotactic radiosurgery for arteriovenous malformations, Part 1: management of Spetzler-Martin Grade I and II arteriovenous malformations. J Neurosurg 116:11-20, 2012

42. Kihlström L, Guo WY, Karlsson B, Lindquist C, Lindqvist M: Magnetic resonance imaging of obliterated arteriovenous malformations up to 23 years after radiosurgery. J Neurosurg 86:589-593, 1997

43. Kim HY, Chang WS, Kim DJ, Lee JW, Chang JW, Kim DI, et al: Gamma Knife surgery for large cerebral arteriovenous malformations. J Neurosurg 113 Suppl:2-8, 2010

44. Kim MS, Lee SI, Sim JH: A case of very large cyst formation with Gamma Knife radiosurgery for an arteriovenous malformation. Stereotact Funct Neurosurg 72 (Suppl 1):168-174, 1999

45. Liu W, Ye X, Zhao Y, Wang S, Zhao J: Clinical and pathological changes in cerebral arteriovenous malformations after stereotactic radiosurgery failure. Chin Med J (Engl) 121:1076-1079, 2008

46. Malikova H, Koubska E, Vojtech Z, Weichet J, Syrucek M, Sroubek J, et al: Late morphological changes after radiosurgery of brain arteriovenous malformations: an MRI study. Acta Neurochir (Wien) 158:1683-1690, 2016

47. Maruyama K, Shin M, Tago M, Kurita H, Kawahara N, Morita A, et al: Management and outcome of hemorrhage after Gamma Knife surgery for arteriovenous malformations of the brain. J Neurosurg 105 Suppl:52-57, 2006

48. Matsuo T, Kamada K, Izumo T, Hayashi N, Nagata I: Cyst formation after linac-based radiosurgery for arteriovenous malformation: examination of predictive factors using magnetic resonance imaging. Clin Neurol Neurosurg 121:10-16, 2014

49. Moosa S, Chen CJ, Ding D, Lee CC, Chivukula S, Starke $\mathrm{RM}$, et al: Volume-staged versus dose-staged radiosurgery outcomes for large intracranial arteriovenous malformations. Neurosurg Focus 37(3):E18, 2014

50. Mouchtouris N, Jabbour PM, Starke RM, Hasan DM, Zanaty M, Theofanis T, et al: Biology of cerebral arteriovenous malformations with a focus on inflammation. J Cereb Blood Flow Metab 35:167-175, 2015

51. Nakajima H, Yamanaka K, Ishibashi K, Iwai Y: Delayed cyst formations and/or expanding hematomas developing after Gamma Knife surgery for cerebral arteriovenous malformations. J Clin Neurosci 33:96-99, 2016

52. Oermann EK, Ding D, Yen CP, Starke RM, Bederson JB, Kondziolka D, et al: Effect of prior embolization on cerebral arteriovenous malformation radiosurgery outcomes: a casecontrol study. Neurosurgery 77:406-417, 2015

53. Oermann EK, Rubinsteyn A, Ding D, Mascitelli J, Starke RM, Bederson JB, et al: Using a machine learning approach to predict outcomes after radiosurgery for cerebral arteriovenous malformations. Sci Rep 6:21161, 2016

54. Pan HC, Sheehan J, Stroila M, Steiner M, Steiner L: Late cyst formation following Gamma Knife surgery of arteriovenous malformations. J Neurosurg 102 Suppl:124-127, 2005

55. Pollock BE, Brown RD Jr: Management of cysts arising after radiosurgery to treat intracranial arteriovenous malformations. Neurosurgery 49:259-265, 2001

56. Pollock BE, Gorman DA, Coffey RJ, Friedman WA, Riina HA, Gutin PH, et al: Patient outcomes after arteriovenous malformation radiosurgical management: Results based on a 5- to 14-year follow-up study. Neurosurgery 52:1291-1297, 2003

57. Przybylowski CJ, Ding D, Starke RM, Yen CP, Quigg M, Dodson B, et al: Seizure and anticonvulsant outcomes following stereotactic radiosurgery for intracranial arteriovenous malformations. J Neurosurg 122:1299-1305, 2015

58. Shuto T, Ohtake M, Matsunaga S: Proposed mechanism for cyst formation and enlargement following Gamma Knife surgery for arteriovenous malformations. J Neurosurg 117 Suppl:135-143, 2012

59. Shuto T, Yagishita S, Matsunaga S: Pathological characteristics of cyst formation following Gamma Knife surgery for arteriovenous malformation. Acta Neurochir (Wien) 157:293-298, 2015

60. Starke RM, Kano H, Ding D, Lee JYK, Mathieu D, Whitesell $\mathrm{J}$, et al: Stereotactic radiosurgery for cerebral arteriovenous malformations: evaluation of long-term outcomes in a multicenter cohort. J Neurosurg 126:36-44, 2017

61. Starke RM, Yen CP, Chen CJ, Ding D, Mohila CA, Jensen $\mathrm{ME}$, et al: An updated assessment of the risk of radiationinduced neoplasia after radiosurgery of arteriovenous malformations. World Neurosurg 82:395-401, 2014

62. Yamamoto M, Hara M, Ide M, Ono Y, Jimbo M, Saito I: Radiation-related adverse effects observed on neuro-imaging several years after radiosurgery for cerebral arteriovenous malformations. Surg Neurol 49:385-398, 1998 
63. Yamamoto M, Ide M, Jimbo M, Hamazaki M, Ban S: Late cyst convolution after Gamma Knife radiosurgery for cerebral arteriovenous malformations. Stereotact Funct Neurosurg 70 (Suppl 1):166-178, 1998

64. Yamamoto M, Jimbo M, Hara M, Saito I, Mori K: Gamma Knife radiosurgery for arteriovenous malformations: longterm follow-up results focusing on complications occurring more than 5 years after irradiation. Neurosurgery 38:906914, 1996

65. Yang W, Porras JL, Garzon-Muvdi T, Xu R, Caplan JM, Hung AL, et al: Management outcome of brainstem arteriovenous malformations (AVMs): the role of radiosurgery. World Neurosurg 94:64-72, 2016

66. Yang W, Porras JL, Hung AL, Khalid S, Garzon-Muvdi T, Caplan JM, et al: Risk of hemorrhage in patients over age 60 with arteriovenous malformations (AVMs). J Clin Neurosci 34:121-127, 2016

67. Yen CP, Matsumoto JA, Wintermark M, Schwyzer L, Evans AJ, Jensen ME, et al: Radiation-induced imaging changes following Gamma Knife surgery for cerebral arteriovenous malformations. J Neurosurg 118:63-73, 2013

68. Yen CP, Monteith SJ, Nguyen JH, Rainey J, Schlesinger DJ, Sheehan JP: Gamma Knife surgery for arteriovenous malformations in children. J Neurosurg Pediatr 6:426-434, 2010
69. Yen CP, Steiner L: Gamma Knife surgery for brainstem arteriovenous malformations. World Neurosurg 76:87-95, $57-58,2011$

\section{Disclosures}

The authors report no conflict of interest concerning the materials or methods used in this study or the findings specified in this paper.

\section{Author Contributions}

Conception and design: Ilyas, Ding. Acquisition of data: Ilyas. Analysis and interpretation of data: Ilyas, Chen. Drafting the article: Ilyas. Critically revising the article: all authors. Reviewed submitted version of manuscript: all authors. Approved the final version of the manuscript on behalf of all authors: Sheehan. Statistical analysis: Ilyas, Chen. Administrative/technical/material support: Sheehan. Study supervision: Sheehan.

\section{Correspondence}

Jason P. Sheehan, Box 800212, Department of Neurological Surgery, University of Virginia Health System, Charlottesville, Virginia 22908. email: jsheehan@virginia.edu. 